\title{
Childhood Enuresis: A Study of Dogarawa Community of North Western Nigeria.
}

\author{
Imoudu IA, * Bugaje MA,+ Aikhionbare HA+ \\ *Department of Paediatrics,Federal Medical Centre,Azare,Nigeria. \\ + Department of Paediatrics,Ahmadu Bello University,Zaria, Nigeria.
}

\begin{abstract}
This study aimed at determining the prevalence and factors associated with enuresis in Dogarawa community of Kaduna state, North western Nigeria. Using a structured questionnaire, the prevalence of enuresis was determined amongst apparently healthy 300 children aged 5-17 years from $15^{\text {th }}$ September, 2010 to $20^{\text {th }}$ January, 2011.The prevalence of enuresis was $26.3 \%$. Males accounted for $69.6 \%$ (55 subjects) while females made up $30.4 \%$ (24 subjects) of those who were enuretic. The relationship between gender and prevalence of enuresis was statistically significant $\left(\chi_{c}{ }^{2}=8.92, d f=1, p<0.05\right)$. All the enuretic children had primary enuresis, no case of secondary enuresis was recorded. There was also no case of strict diurnal enuresis. Sixty-five (21.7\%) of the enuretic children had strict nocturnal enuresis and 14 (4.7\%) had combined nocturnal and diurnal enuresis. The prevalence of enuresis decreased with increasing age and this was statistically significant $\left(\chi^{2}=16.3, d f=3, p<0.05\right)$.Although not statistically significant, enuresis was commoner in children from low socio-economic background and amongst first order births. There was a positive association between family history of bedwetting and prevalence of enuresis $\left(\chi_{c}^{2}=124.2, d f=4, p<0.05\right)$. The high prevalence of enuresis in this community warrants further studies and appropriate interventional measures.
\end{abstract}

Keywords: Childhood, Enuresis, Dogarawa, Enuretic, Prevalence.

\section{Introduction}

Enuresis is a disease many children and their families commonly confront. ${ }^{1}$ It is a worrying condition that involves repeated voiding of urine into clothes or bedclothes that persist beyond the normative age of maturation of urinary control. ${ }^{2}$ Enuresis may be classified as nocturnal, diurnal or both. It can also be classified as primary or secondary consistent with the fashion of its onset. ${ }^{3}$ The prevalence estimates of enuresis are highly variable, with a range of $3.8 \%$ to $35 \%$ published across studies. ${ }^{2-5}$ The disparate estimates can be accounted for primarily by the differences in the definitions of enuresis, different diagnostic criteria, differences in the age range and ethnicity of children and reference periods for prevalence rates (e.g., point prevalence versus 12month prevalence), as well as cultural differences. ${ }^{2,6}$ It is approximately twice as common in boys as in girls. ${ }^{2,7}$

Further than genetic factors, the aetiology of enuresis likely involves a complicated network of organic and psychological factors. Enuresis is frequently encountered where socio-economic risk factors such as low levels of income, lack of education in parents, expanded family structures, environments of inferior social status are prevalent. It is also common among institutionalized children. ${ }^{8,9}$ Enuresis is also known to be associated with organic conditions like sickle cell anaemia, diabetes mellitus, urinary tract infection and diabetes insipidus. ${ }^{10}$

There is a dearth of data on enuresis in Northern Nigeria. The few available studies are hospital based studies and as such might not reflect the true state in the communities. The objective of this study is to determine the prevalence of enuresis in children aged 5-17 years in Northern Nigeria, using a community-based approach and also to evaluate the relationship between the prevalence of enuresis and some socio-demographic factors.

\section{Materials And Methods}

The study was descriptive cross-sectional in design. Permission was obtained from the Ethical Committee of the Ahmadu Bello University Teaching hospital Zaria in advance of the commencement of the study. Applying appropriate formula, 300 apparently healthy children aged 5-17 years were recruited from Dogarawa community using the multistage sampling technique from 15th September 2010 to 20th January 2011. Dogarawa is a rural community in Sabon Gari Local Government Area of Kaduna State.

A structured questionnaire was employed for data collection. Section I was directed at the parents or guardians and section II was directed at the child. Socio-demographic information of the families and the child as well as features of enuresis when present, were obtained. Enuresis in this study was defined as involuntary passage of urine into bed or clothes (after the fifth birthday) at least 2 times a week for 3 consecutive months. Secondary enuresis was defined as recurrence of bedwetting after a child had been previously dry for 6 consecutive 
months. Diurnal enuresis was defined as involuntary voiding of urine during waking hours while night time bedwetting was classified as nocturnal enuresis. Each questionnaire had a code number that was used to identify the child. The questionnaire consisted of 28 questions and was filled out by the researchers following direct questioning of the mothers.

The collected data was entered into the statistical package for social science software (SPSS) version 16. Significance of difference in proportions between groups or classes was determined using the chi-square test (Yates continuity correction of chi-square test was applied were required). A p value of less than 0.05 was regarded as being statistically significant.

\section{Results}

The total number of children studied was 300. They were aged 5-17 years. Of the children studied, 159 (53\%) were males while $141(47 \%)$ were females, giving a male to female ratio of 1.1:1. The modal age range of the children studied was 5-7 years, mean age $9.57 \pm 3.3$ years and the median age 9 years.

Prevalence of enuresis

A total of 79 of the 300 children studied were found to have enuresis, giving a prevalence of $26.3 \%$. The majority of the children with enuresis were aged 5-7 years (49.4\%), with a median age of 8 years and a modal age of 6 years. The mean age of the children with enuresis of $8.23 \pm 2.7$ years did not vary significantly $\left(\chi^{2}=4.87, p>0.05\right)$ from that of those who did not have enuresis $(10.05 \pm 3.4$ years $)$. Table I shows the prevalence of enuresis by age. Only $5(1.6 \%)$ of the enuretic children were aged 14-17 years as against 39 (13.0\%) aged 5-7 years. The prevalence of enuresis decreased with increasing age. The relationship between age and enuresis was statistically significant $(\mathrm{p}=0.001)$.

Fifty-five (18.3\%) of the enuretic children were boys, while 24 (8\%) were girls. A total of (55) $34.5 \%$ of all the boys studied were enuretic, whereas (24) $17.0 \%$ of the girls studied had enuresis, and the difference was statistically significant $(\mathrm{p}=0.003)$.

Types of Enuresis

Sixty-five (21.7\%) of the subjects had only nocturnal enuresis, and (14) $4.7 \%$ had combined nocturnal and diurnal enuresis. None of the study subjects had only diurnal enuresis. Both nocturnal, and combined nocturnal and diurnal enuresis were commoner in males (prevalence of $14 \%$ and $3.7 \%$ respectively). No child aged 14-17 years was amongst those who had combined nocturnal and diurnal enuresis, but 5 of them (aged 14-17 years) had only nocturnal enuresis. Twenty-nine children aged 5-7 years had isolated nocturnal enuresis and $10(3.3 \%)$ had combined nocturnal and diurnal enuresis respectively. The prevalence of nocturnal and combined nocturnal and diurnal enuresis amongst children aged 5-7 years was hence 9.7\% and 3.3\% respectively. All 79 enuretic children had primary enuresis, and none had secondary enuresis.

Socio-economic status of the families

Majority $52(17.4 \%)$ of the enuretic children were from families of low socio-economic status, $4(1.3 \%)$ were from the upper class and 23(7.7\%) were drawn from the middle class. The relationship between enuresis and socio-economic status was not statistically significant, $\left(\chi_{c}{ }^{2}=1.5, \mathrm{df}=2, \mathrm{p}>0.05\right)$ as shown in Table II.

The relationship between birth order and prevalence of enuresis

Table III shows that enuresis was more frequent in first order births $22(7.3 \%)$, but the relationship between birth order and enuresis was not statistically significant $\left(\chi^{2}=7.7, \mathrm{df}=4, \mathrm{p}>0.05\right)$.

Prevalence of enuresis in relation to family history of enuresis.

A positive family history of enuresis was common amongst the children found to be enuretic. Sixtythree of them (21\%) had a family member who either was enuretic or had been in the past. There were 53 siblings of enuretic children, 6 cousins and 2 uncles. One mother and no father admitted to have been enuretic. The relationship between family history of enuresis and enuresis was statistically significant $\left(\chi_{c}{ }^{2}=124.2, \mathrm{df}=4, \mathrm{p}\right.$ $=0.0001)$. Table IV shows this relationship.

\section{Discussion}

Enuresis is a common health problem, ${ }^{6,11,12}$ and this fact has been succinctly attested to by the finding in this study of a prevalence of $26.3 \%$. This prevalence figure is for nocturnal enuresis as well as combined diurnal and nocturnal enuresis. Diurnal enuresis as a single entity was not seen in this study. This, furthermore demonstrates consistency with the widely held view that diurnal enuresis is a rare disease. An overall prevalence of 26.3\% in Dogarawa community is significantly higher than published prevalence figures from Europe(3-7\%), North America(4.8\%) and Asia(6.8\%,7.6\%), ${ }^{2,10,13,14}$ Drawing a comparison between the prevalence obtained in this study and those of the previous published community based surveys on childhood enuresis in Nigeria shows that this figure is higher than the $17.6 \%$ obtained from a rural community in Oyo state ${ }^{15}$ in 2003 by Osungbade 
and Oshiname, as well as the $21.3 \%$ obtained from the one conducted by Iduoriyekemwen et al in Ehor, Edo state in $2002 .^{6}$ The basis for this disparity in prevalence figures within the same country is not readily evident. However, the prevalence of enuresis has been said to be influenced by such factors as ethnicity and culture ${ }^{2,6}$ Furthermore, autosomal recessive mode of inheritance has been implicated in the causation of some cases of primary nocturnal enuresis ${ }^{16}$ and the fact that consanguineous (first cousin) marriages are not infrequent in Dogarawa community can further attest to this fact.

The prevalence of nocturnal enuresis in this study was $21.7 \%$ while that of combined nocturnal and diurnal enuresis was $4.7 \%$. The figure for combined nocturnal and diurnal enuresis is higher than figures obtained from a previous Nigerian study $(2 \%),{ }^{6}$ and those from India, Korea as well as North America(1.5$2.8 \%){ }^{13,17,18}$ Nevertheless, the figure confirms the fact that combined diurnal and nocturnal enuresis is not common. The $21.7 \%$ prevalence of nocturnal enuresis in this study compares favourably with figures from a Jordanian study $(23.8 \%){ }^{14}$ but remains higher than those from Turkey (14.9\%) ${ }^{19}$ and Ehor, Edo state, Nigeria $(19.3 \%) .{ }^{6}$ Differences in age defining criteria of study population as well as the aforementioned reasons (that explain the higher overall prevalence in this study) could account for these observed discrepancies. This study demonstrated that the prevalence of enuresis decreases with increasing age which is in conformity with various other studies. ${ }^{6,17}$ The prevalence at 6 years was $6.3 \%$ and at 10 years it dropped to $3 \%$. The reason put forward for the decreasing prevalence of enuresis with increasing age is that, most cases of enuresis are caused by developmental immaturity of voiding control, and as such most children with enuresis ultimately acquire normal control with increasing age and maturity. ${ }^{20}$

Enuresis was commoner in boys than girls in this study. This is in conformity with generally acknowledged findings. ${ }^{10,20}$ Several workers have tried to suggest reasons for this higher prevalence in males, including the fact that boys mature more slowly and show more frequent developmental lag, making them less responsive to parental toilet training. ${ }^{21}$ One could also speculate that boys are more active resulting in their being more exhausted at night and less likely to be aroused by a full bladder.

Enuresis was seen to be more frequent in children from low socio-economic background in this study. The relationship between enuresis and socio-economic status however, was not statistically significant. This is in agreement with findings from an earlier community-based Nigerian study, ${ }^{6}$ and an American study conducted in $2009 .^{2}$ Conversely, studies from Turkey and the United Arab Emirates ${ }^{22,23}$ have demonstrated a significant relationship between enuresis and socio-economic status. The increased occurrence of enuresis in children from families of low socio-economic background may be due to the fact that such families are large with little or no child spacing. ${ }^{6}$ Mothers consequently may pay minimal attention to toilet training at the time it is essential. Another frequently associated problem in these families, is a high level of illiteracy (lack of western education) which could negatively impact health seeking behaviour. ${ }^{13}$

Though the relationship was not statistically significant, enuresis was noted in this study to be commoner in first order births. This corresponds to the findings of Hansakunachai ${ }^{24}$ and Iduoriyekemwen et al, ${ }^{6}$ who found that it was commoner in first born children although this was not statistically significant. On the contrary, Cher et al, ${ }^{25}$ working in Taiwan demonstrated a statistically significant relationship between enuresis and birth order. The observed rate of occurrence of enuresis among first born children in this study could be a consequence of maternal inexperience at toilet training during the immediate periods following their first deliveries. This may be due to the prevailing cultural practice of girls being married out in their teenage years, resulting in the mothers not being experienced enough to administer toilet training to their first born children.

This survey found that $63(21 \%)$ of the enuretic children had a family member who was or had been enuretic in the past. On the other hand, 50(16.9\%) of the non-enuretics had a positive family history. This finding is in conformity with those of other studies. ${ }^{6,13,23,25}$ However, the value is higher than that reported in a previous Nigerian study(29 subjects with a positive family history out of 64 enuretic subjects). ${ }^{6}$ This may be ascribed to genetic variations between the different study populations as well as the widespread practice of marriages of consanguinity in Dogarawa community. Genetic factors have long been recognised in enuresis and familial clustering has been observed in several studies. Arnellet $\mathrm{al}^{16}$ demonstrated autosomal dominant inheritance pattern in $43 \%$, and apparent autosomal recessive transmission in $9 \%$ of cases in a Swedish study. The role of history of enuresis amongst parents in this study was however, not observed to be significant. This may have stemmed from the fact that most parents (especially in the presence of their children) were not prepared to reveal their past medical history as it relates to enuresis owing to its stigmatizing nature. ${ }^{6}$

To conclude, enuresis is clearly associated with a positive family history of the problem, commoner in boys and occurs frequently enough to merit a high index of suspicion from those involved in paediatric patient care.

\section{Acknowledgement}

We are grateful to the children, mothers, fathers, and village heads of Dogarawa community for their contribution to the success of this study. 
TABLES Table I.The relationship between age and prevalence of enuresis.

\begin{tabular}{llll}
\hline $\begin{array}{l}\text { Age groups of children } \\
\text { (years) }\end{array}$ & $\begin{array}{l}\text { Enuretic children } \\
\mathrm{n}(\%)\end{array}$ & Non-enuretic children $\mathrm{n}(\%)$ & $\begin{array}{l}\text { Total number of children } \\
\mathrm{n}(\%)\end{array}$ \\
\hline $5-7$ & $39(13.0)$ & $62(20.7)$ & $101(33.7)$ \\
$8-10$ & $23(7.7)$ & $67(22.3)$ & $90(30.0)$ \\
$11-13$ & $12(4.0)$ & $45(15.0)$ & $57(19.0)$ \\
$14-17$ & $5(1.6)$ & $47(15.7)$ & $52(17.3)$ \\
Total & $79(26.3)$ & $221(73.7)$ & $300(100)$ \\
\hline
\end{tabular}

$\left(\chi^{2}=16.3, \mathrm{df}=3, \mathrm{p}=0.001\right)$

Table II.The relationship between socio-economic status of the families and prevalence of enuresis.

\begin{tabular}{llll}
\hline $\begin{array}{l}\text { Family's socio-economic } \\
\text { class }\end{array}$ & $\begin{array}{l}\text { Enuretic children } \\
\mathrm{n}(\%)\end{array}$ & Non-enuretic children $\mathrm{n}(\%)$ & $\begin{array}{l}\text { Total } \\
\mathrm{n}(\%)\end{array}$ \\
\hline Upper class & $4(1.3)$ & $13(4.3)$ & $17(5.7)$ \\
Middle class & $23(7.7)$ & $50(16.7)$ & $73(24.3)$ \\
Lower class & $52(17.3)$ & $158(52.7)$ & $210(70.0)$ \\
Total & $79(26.3)$ & $221(73.7)$ & $300(100)$ \\
\hline
\end{tabular}

$\left(\chi_{\mathrm{c}}^{2}=1.5, \mathrm{df}=2, \mathrm{p}=0.47\right)$

Table III: The relationship between birth order and prevalence of enuresis

\begin{tabular}{llll}
\hline Birth order & $\begin{array}{l}\text { Enuretic children } \\
\mathrm{n}(\%)\end{array}$ & Non-enuretic children $\mathrm{n}(\%)$ & $\begin{array}{l}\text { Total } \\
\mathrm{n}(\%)\end{array}$ \\
\hline First & $22(7.3)$ & $12(4)$ & $34(11.3)$ \\
Second & $9(3)$ & $28(9.3)$ & $37(12.3)$ \\
Third & $17(5.7)$ & $32(10.7)$ & $49(16.4)$ \\
Fourth & $10(3.3)$ & $37(12.4)$ & $47(15.7)$ \\
Fifth and above & $21(7)$ & $112(37.3)$ & $133(44.3)$ \\
Total & $79(26.3)$ & $221(73.7)$ & $300(100)$ \\
\hline
\end{tabular}

$\left(\chi^{2}=7.7, \mathrm{df}=4, \mathrm{p}=0.103\right)$.

Table IV: Prevalence of enuresis in relation to family history of enuresis.

\begin{tabular}{|c|c|c|}
\hline Relationship to an enuretic child & No of enuretic children (\%) & No of non-enureticchildren $(\%)$ \\
\hline Sibling & $53(17.7)$ & $0(0)$ \\
\hline Cousin & $6(2.0)$ & $1(0.4)$ \\
\hline Uncle & $2(0.7)$ & $15(5)$ \\
\hline Aunt & $1(0.3)$ & $12(4)$ \\
\hline Parent & $1(0.3)$ & $0(0)$ \\
\hline No family history & $16(5.3)$ & $193(64.3)$ \\
\hline Total & $79(26.3)$ & $221(73.7)$ \\
\hline
\end{tabular}

$\left(\chi_{c}^{2}=124.2, \mathrm{df}=4, \mathrm{p}=0.000\right)$. 


\section{References}

[1]. Erdogan A, Akkurt H, Boettjer NK, et al. Prevalence and behavioural correlates of enuresis in young children. J Paediatr Child Health. 2008; 44(5):297-301.

[2]. Shreeram S, He JP, Kalaydjian A, Brothers S, Merikangas KR. Prevalence of enuresis and its association with attention deficit/hyperactivity disorder among U.S. children: results from a nationally representative study. J Am Acad child Adolesc Psychiatry 2009; 48 (1):35 - 41.

[3]. Gulumser D, Sevim S, Serap B, Saadet Y. Prevalence of nocturnal enuresis and related factors in children aged 5-13 in Istanbul. Iran J Pediatr. 2012; 22(2): 205-12.

[4]. Ozkan KU, Garipardic M, Toktamist A, Karabiber H, Sahinkanat T. Enuresis prevalence and accompanying factors in school children: a questionnaire study from southeast Anatolia.UrolInt 2004; 73 (2): 149-55.

[5]. Bourquia A, Chihabeddine K. Enuresis: epidemiological study in Moroccan children. Saudi J Kidney Dis Transpl 2002; 12(2):1514.

[6]. Iduoriyekemwen NI, Ibadin MO, Abiodun PO. Survey of childhood enuresis in Ehor community of Edo State, Nigeria. Saudi J Kidney Dis transpl 2006; 17(2):177 - 82.

[7]. Yeung CK, Sreedhar B, Sihoe JD, Sit FK, Lau J. Differences in characteristics of nocturnal enuresis between children and adolescents: a critical appraisal from a large epidemiological study. BJU Int 2006; 97(5):1069-73.

[8]. Gür E, Turhan P, Can G, et al. Enuresis: prevalence, risk factors and urinary pathology among school children in Istanbul, Turkey. Pediatr Int. 2004;46 (1):58-63.

[9]. Öge O, Kocak I, Gemalmaz H. Enuresis: Point prevalence and associated factors among Turkish children.JPediatr. 2001;43 (1):3843.

[10]. Boris NW, Dalton R. Enuresis (Bed-wetting). In: Behrman RE, Kliegman RM, Jenson HB, editors.Nelson textbook of pediatrics.17th edition. Philadelphia: WB Saunders (publishers), 2004; 74-5.

[11]. Caldwell PH, Edgar D, Hodson E, Craig JC. Bedwetting and toileting problems in children. Med J Aust 2005 ; 182 (4): $190-5$.

[12]. Unalacak M, Sogut A, Aktunc E, Demircan N, Altin R. Enuresis nocturna and risk factors among school age children in Northwest Turkey. Eur J Gen Med 2004; 1(3): 21-5.

[13]. De Sousa A, Kapoor H, Jagtap J, Sen M. Prevalence and factors affecting enuresis. Indian J Urol 2007; 23:354-7.

[14]. Hazza I, Tarawneh H. Primary nocturnal enuresis among school children in Jordan. Saudi J Kidney Dis transpl 2002; 13 (4): 478 80.

[15]. Osungbade KO, Oshiname FO. Prevalence and perception of nocturnal enuresis in children of a rural community in Southwestern Nigeria. Trop Doct 2003; 3 (4): $234-6$.

[16]. Arnell H, Hjalmas K, Jagervall M, Lackgren G, Stenberg A, Bengtsson B, et al. The genetics of primary nocturnal enuresis: inheritance and suggestion of a second major gene on chromosome 12q. J Med Genet 1997; 34: 360 - 5.

[17]. Safaninejad MR. Prevalence of nocturnal enuresis, risk factors, associated familial factors and urinary pathology among school children in Iran. J PediatrUrol 2007; (6):443-52.

[18]. Lee SD, Sohn DW, Lee JZ. An epidemiological study of enuresis in Korean children. BJU Int 2000; 85: 869-73.

[19]. Gunes A, Gunes G, Acik Y, Akilli A. The epidemiology and factors associated with nocturnal enuresis among boarding and daytime school children in southeast of Turkey: across sectional study. BMC Public Health 2009; 9:357-8.

[20]. Ozden C, Ozdal OL, Altino S, Oguzulgen I, Urgancioglu G, Memis A. Prevalence and associated factors of enuresis in Turkish children. IntBraz J Urol 2007; 33: 216-22.

[21]. Garfinkel BO. The elimination disorders. In: Garfinkel BO, Carlson GA, Weller EB, editors. Psychiatric disorders in children and adolescents.2nd edition. Philadelphia: WB Saunders (publishers), 2000; $326-36$

[22]. Unalacak M, Sogut A, Aktunc E, Demircan N, Altin R. Enuresis nocturna and risk factors among school age children in Northwest Turkey. Eur J Gen Med 2004; 1(3): 21-5.

[23]. Eapen V, Mabrouk AM. Prevalence and correlates of nocturnal enuresis in the United Arab Emirates. Saudi Med J 2003; 24(1):4951.

[24]. Hansakunachai T. Epidemiology of enuresis among school- age children in Thailand. J Dev Behav Pediatr 2005; 26(5):356-60.

[25]. Cher TW, Lin GJ, Hsu KH. Prevalence of nocturnal enuresis and associated familial factors in primary school children in Taiwan. J Urol 2002; 168: 1142-6. 